\title{
Public-private partnerships, part 2: calculations of risk
}

Canada's 3 most populous provinces Ontario, Quebec and British Columbia - have been shifting from traditional public sector procurement methods to public-private partnerships to design, build, finance, maintain and, sometimes, operate hospitals. Part 1 of this series (CMAJ 2008;179[9]:883-5) featured a primer of this sea change, which has gone largely unexamined by health professionals, academics and the public.

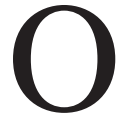

ntario had already invited 3 private sector consortia to bid to build, finance, maintain and operate services at a 289-bed hospital in Sault Ste. Marie, Ontario, when Dr. Michael Gardam submitted his report on a deadly outbreak of Clostridium difficile at the existing Sault Area Hospital.

Gardam, director of infection prevention and control at Toronto's University Health Network, had been brought to the Soo to investigate the fall 2006 outbreak that led to the deaths of 18 patients.

In addition to calling for measures to reduce infection rates in the existing hospital, Gardam recommended the number of private rooms in the new hospital be increased to $80 \%$ from the planned approximately $25 \%$.

The province agreed to revise the hospital plans, hiking the proportion of single occupancy rooms to $45 \%$, and the consortia were given more time to bid.

Had the timing been different - if construction had already begun before the outbreak, Gardam's report, and the revised hospital plans - the province and the hospital board would have found themselves facing expensive change orders made more complicated by the fact that they were dealing with not 1 or 2 individual companies, but a consortium of many different firms and a complex legal agreement.

Critics say the evolving nature of hospital use is one reason to decry the recent proliferation of public-private partnership (P3) hospitals, in which governments are tied into extremely detailed, decades-long contracts with pri-

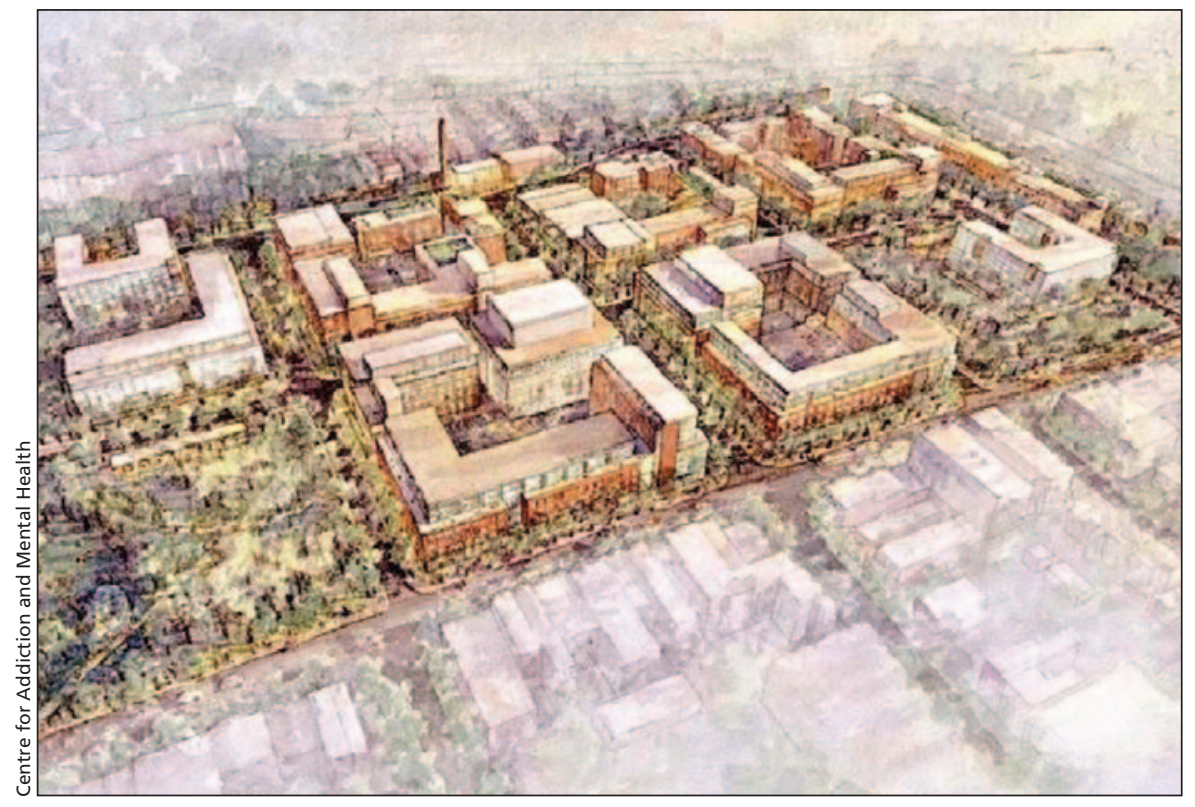

Artist's drawing of redevelopment plans for the Queen Street, Toronto, site of the Centre for Addiction and Mental Health. Phase 1 of the multi-year development project was opened in June.

vate consortia. "If you look at what has happened to patterns of hospital utilization in the past 2 decades, they've changed radically and dramatically," says Robert Evans, a University of British Columbia health care economist.

Debate over the merits of P3 hospitals is highly polarized, but there's little argument about the need to update or replace aging hospitals neglected during years of spending restraints and deficit phobia.

Certainly, the P3 projects are enthusiastically supported as a way to get hospitals built sooner. Ontario Hospital Association President Tom Closson says the advent of partnerships "has encouraged the government to make decisions on a hundred different hospital capital projects since 2004." Ontario is in the midst of a \$5-billion hospital building boom, which includes 19 partnership hospitals under construction and another 7 deals close to completion.

But Pamela Fralick, who chaired the Centre for Addiction and Mental Health in Toronto when it settled on a
P3 model for redevelopment on its sprawling 10.9 hectare Queen Street West site, says the model places administrators in a quandary. "It is a tough dilemma for [hospital] boards. We know the downside [of public-private partnerships]."

"We know there is money involved and there are risks and transparency issues, but in the end ... we have something [built] in 5 to 7 years as opposed to possibly never," adds Fralick, now president of the Canadian Healthcare Association, which represents hospitals and regional health authorities. Her organization has urged the federal government to create a national program for investment in capital infrastructure for health but has taken no position on the merits of hospital public-private partnerships.

It is interesting, she notes, that some provincial governments are actively urging hospital boards to look at P3s. "So rather than shying away, there is an encouragement."

But critics of the P3 model, mostly health coalitions and unions, argue that 
P3s invariably cost the public more and leave it with less control. In the case of the new hospital in Sault Ste. Marie, the long-term obligations for debt repayment, maintenance and operating costs amount to $\$ 28.7$ million annually over 30 years, according to Infrastructure Ontario.

Critics also contend that the task of managing hospitals becomes more difficult. Instead of traditional procurement methods, where everyone answers to the hospital board, P3 financiers call many of the shots, and their interest is in maximizing profit and minimizing risk to themselves, says Natalie Mehra, director of the Ontario Health Coalition. "P3s are misaligned with Canada's main health policy goals - to provide flexible infrastructure that will provide the most services for the most people possible. Remember, most towns only get a new hospital once in every 50 or more years."

If there is one thing that critics and proponents agree upon, it's that with the new model for hospital development, "the devil is in the details."

And there are mountains of them, as evidenced when, after nearly 4 years of legal wrangling, the Ontario Health Coalition and 3 unions gained access to previously confidential documents about the William Osler Health Centre in Brampton, the first hospital in Ontario to be built under the publicprivate partnership model.

Lawyers and accountants were faced

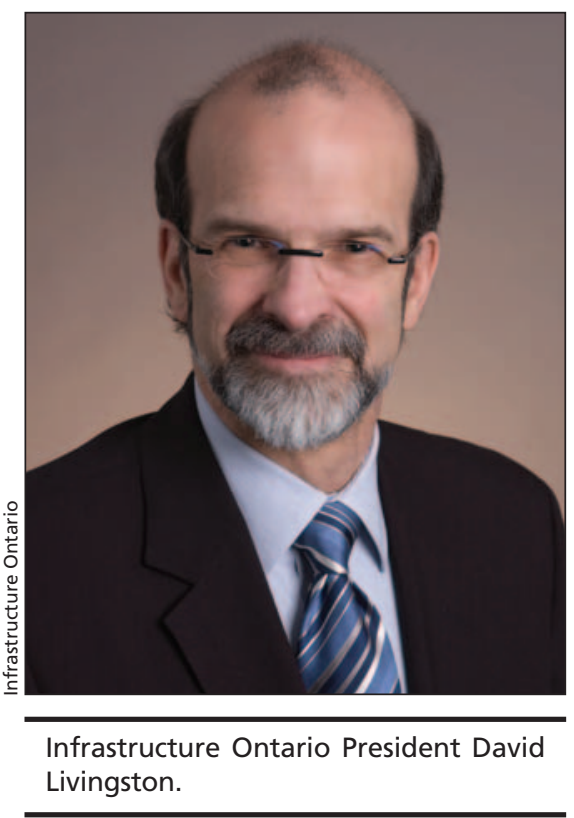

with the task of sorting through 3 piles of documents: those pertaining to the agreement between the hospital and the private consortium; those pertaining to the funding agreement between the province and the hospital; and finally, those describing the relationships among the consortium's multiple private participants, even if it costs more in the long term, than make an upfront commitment of a substantial amount of money that might go to more politically visible or popular programs, notes Glenn Brimacombe, chief executive officer of the Association of Canadian Academic Healthcare Organizations, which has taken no offi-

\section{"We always thought you Canadians were more savvy because you understood that the way to get in is through the infra- structure." - Dr. Allyson Pollock}

including builders, pension funds, service providers and financiers.

Lawyer Steven Shrybman, from the Ottawa office of the law firm Sack, Goldblatt Mitchell calls the latter heap "a huge complex contractual investment edifice" involving elaborate tax planning schemes. The documents in that pile were not given to, or reviewed by, the province before the deal was approved, says Shrybman, who acted for the coalition. But the Ontario Auditor General is now reportedly examining the deal.

No less involved and complex are the myriad arguments and opinions surrounding the new model of financing and building hospitals, which can be broadly grouped into 4 areas: cost, flexibility, transparency and public interest.

\section{Cost considerations}

The rationale for public-private partnerships has shifted over time. When they were first promoted, in Ontario and British Columbia, P3s were seen as means for governments to make capital expenditures without having to expense the cost of the project in the year of acquisition, as they had to do, under the then-prevalent government cash accounting system.

But the recent shift away from cash to accrual accounting - which essentially allows for depreciation of major expenditures - eliminated the bookkeeping advantage.

Still, an abiding appeal for governments is that, in a world of competing demands, they may prefer to make regular payments to a private consortium, cial position on $\mathrm{P} 3 \mathrm{~s}$.

David Livingston, president of Infrastructure Ontario, which helps facilitate these deals, acknowledges that financing costs are higher than for traditional projects. That's because governments can raise money less expensively than the private sector can for P3 arrangements. Transaction costs for $\mathrm{P} 3 \mathrm{~s}$ are also higher, due to the complexity of legal agreements that must be negotiated.

But those higher costs are offset by the value of the "risk transfer" to the private sector, in which the consortium agrees to assume the risk of delivering projects on budget and on time, says Livingston.

These value-for-money calculations are a "mathematical puzzle and in the end the math has to prove that there is value for doing it." For example, Livingston's agency calculates that while the basic cost of the new Sault Ste. Marie hospital would be lower if the public sector financed and negotiated the procurement, the $\mathrm{P} 3$ risk transfer advantage means taxpayers will save $\$ 101.7$ million on the cost of the hospital's development, which is now pegged at $\$ 988$ million over the 30-year deal.

But the public documents don't provide details on exactly how that risk transfer calculation was made and the $\$ 101.7$ million amounts to "a very expensive insurance policy" says Lewis Auerbach, an Ottawa consultant and former director of audit operations for the Auditor General of Canada.

Auerbach argues there is less than 
meets the eye to the risk transfer advantage since companies build and operate facilities with limited liability, and in the event of large losses on essential public services, "a responsible government will always step in." The current credit crisis in the United States, where the public sector has had to bail out the financial sector for its risky mortgage offerings, "draws attention to where risk ultimately resides," he says.

It is the financing that attracts companies to the P3 model, says Livingston. "We look at the financing of the deal as essentially the thing that incents the private sector to do it fast and do it well, because it is their money on the line and if they miss on something or something happens, the interest clock is ticking on their dime, not ours."

As far as incentives go, there is of course the profit motive and those who help finance these deals appear to stand to do very well. The capital cost of the William Osler Health Centre was pegged at $\$ 550$ million. According to the Ontario Health Coalition, the court documents indicate the partnership will receive roughly $\$ 299$ million in dividends alone over the life of the contract.

Refinancing is also a potential landmine. In fact, refinancing P3 hospital deals proved to be so controversial in the United Kingdom that in May 2006, Edward Leigh, Conservative chair of the Committee of Public Accounts, labelled one of them as "the unacceptable face of capitalism." The refinancing gain on the Norfolk and Norwich Hospital was $£ 116$ million (\$224.7 million) and that essentially "lined the pockets of investors," Leigh noted, arguing that it also significantly hiked the cost to the public (by up to $£ 257$ million more) should it seek to terminate the contract early.

Infrastructure Ontario allows some refinancings, with any profit to be shared 50-50 between the consortium and the hospital. And windfall profits resulting from a change in the consortium's ownership must be shared 50-50 with the hospital, according to a spokesperson.

\section{Flexibility}

As the Sault Ste. Marie hospital experience illustrates, the health care field is constantly changing. In the UK, a change in funding arrangement from block to less predictable per patient funding has left hospitals scrambling to pay their fixed long-term obligations to private consortia, says Dr. Jonathan Fielden of the British Medical Association, which opposes public-private partnerships for hospital development.

Evans concurs. "When you tie yourself to 30-year contracts in a field that changes the way health care changes, it seems to me that you are on very dubious ground." He likens the deals to "the mentality of people who borrow long term on credits cards - you'll have a lot less at the end of the day, but [they say] I don't have to think about it."

But Closson counters that the 30year maintenance contracts are a key attraction. "I've been a hospital CEO myself and one of the things you notice is that boards and CEOs feel pressured to reduce maintenance costs to balance their budgets. This model forces the maintenance of the building."

Closson, who notes the Ontario government did not begin to put large sums of money into capital redevelopment until public-private partnerships became a normal government practice, says Infrastructure Ontario completes and releases independent value audits for each development confirming the financial benefit.

Auerbach says the Infrastructure Ontario bar is nowhere near that high. "There are no audits, only the overall conclusion of assessments ... [the accounting firm] uses a methodology which they helped develop and do not question it. ... Secondly, they state they have relied on the information provided and have not audited it for accuracy or assessed it for plausibility. So while the assessment may formally be independent, it is very limited in what it says."

Change orders are another point of contention. The P3 model facilitates detailed upfront planning in order to minimize costly change orders, says Livingston. "There are a very few good reasons for change orders and many, many bad reasons."

But conventional procurement allows for modifications to design even during construction and this "permits a design to adapt to health care innovations and clinicians to request changes" once they have a more realistic understanding of the design, wrote Thomas Philpot, program manager for public-private partnerships at the McGill University Health Centre (Healthc Manage Forum 2007; 20[4]:33-6). "This is especially relevant to larger projects that may take a number of years to complete but fails to achieve the same degree of risk transfer."

\section{Transparency}

Livingston bristles when asked about the lack of transparency around the public-private partnership deals. "The burden of proof always seems to be on the AFP [alternative financing and procurement, Ontario's term for such deals] side to become more transparent. I've never seen documents posted on a website in traditional procurement."

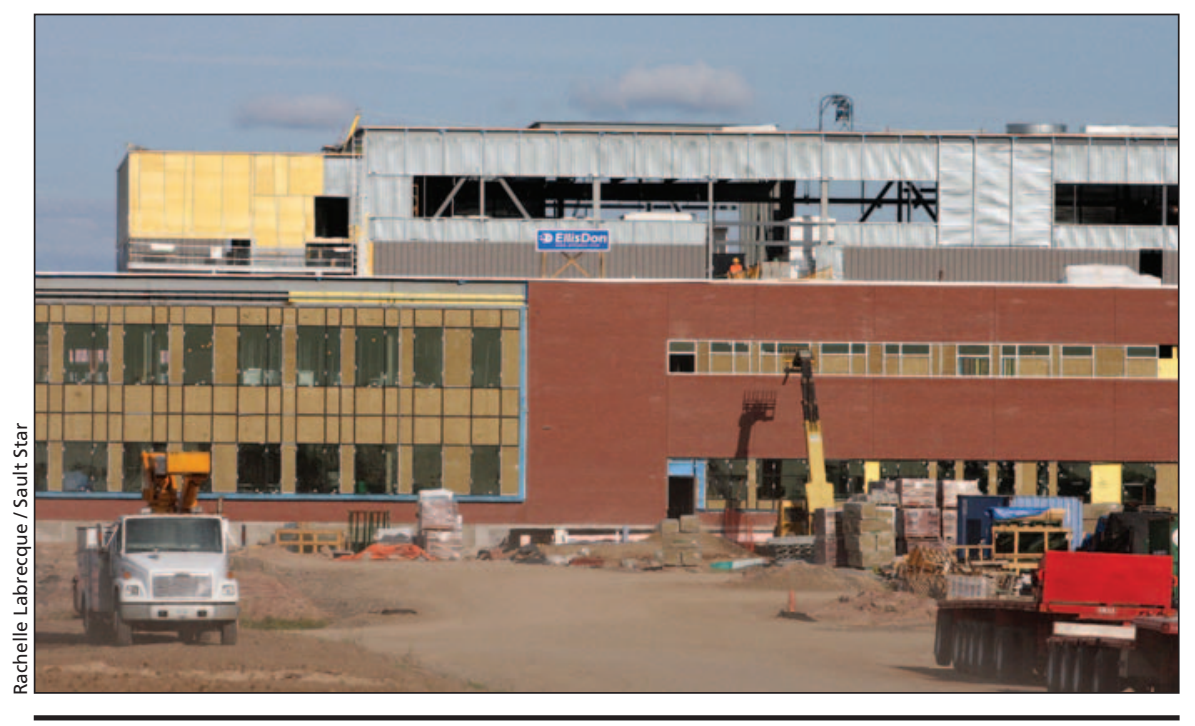

The new 289-bed hospital being built by a public-private partnership in Sault Ste. Marie, Ontario, is projected to cost $\$ 988$ million over the course of a 30-year deal. 
But Philpott notes that critical analysis of the procurement process is greatly handicapped by "an apparent commercial necessity to keep confidential the initial business case and final contracts, even after the procurement process."

And in an otherwise pro-P3 article, Toronto lawyer Timothy J. Murphy, who worked for Aecon Group Inc. on its bid for the Rouge Valley Hospital development in Ajax and Pickering, Ontario, argues that governments must not "succumb to private-sector demands for confidentiality," (Canadian Public Administration 2008;51[1]:99-126). Murphy writes that once $\mathrm{P} 3$ projects are operational, there should be public reporting of performance measures, including penalties for poor performance; information about the mechanisms for complaints and redress, and information about any retendering of the $\mathrm{P} 3$ contract. As well, he calls for policies to prevent bidders from lobbying public officials.

Shrybman, meanwhile, is troubled by the lack of public engagement or debate. He notes, for example, that when P3s were first introduced to Ontario, there were just 2 press releases to "explain this profound shift in public policy around how hospitals will be built. And then Liberals came along claiming they would abandon the model and they don't."

\section{Public interest}

An abiding question is why governments have not seen fit to bolster public sector expertise in negotiating good, tight contracts, and hire their own project managers, rather than enter into deals with private sector consortia, which finance the projects and bundle together a wide variety of tasks.

Livingston says it would not be possible for the province to project manage the numerous hospitals now under construction. "We know the bidders who win these things will step up and do the lion's share of the project management work so our job is more of making sure they do what they are supposed to do and deliver what they agreed."

Others are unconvinced, including Dr. Allyson Pollock, head of the Centre for International Health Policy at the University of Edinburgh and a leading critic of public-private partnerships, who has published on the subject ex- tensively in the British Medical Journal and is the author of NHS plc: The Privatisation of Our Health Care.

Pollock warns that just as Canada is embracing this approach to hospital development, it is being discredited in the United Kingdom. "This is the first threat in the privatization of health care, part of a plethora of policies aimed at breaking up the Canadian health care system. ... We always thought you Canadians were more savvy because you understood that the way to get in is through the infrastructure." - Ann Silversides, CMAJ

DOI:10.1503/cmaj.081633

\section{CMA Secretary General resigns}

Published at www.cmaj.ca on Oct. 9, 2008.

$\mathrm{T}$ he Canadian Medical Association's Secretary General and Chief Executive Officer, William Tholl, has resigned after more than 7 years in the job.

Tholl resigned following discussions with the CMA's Board of Directors, he said in an interview with $C M A J$. "The Board obviously has the obligation to hire or to not. It has nothing to do with Left versus Right or policy differences of that nature. It has everything to do with leadership."

Barbara Drew, who will serve as the acting chief executive officer while the CMA searches for a permanent replacement, would not comment on the circumstances of Tholl's departure, citing privacy issues.

Dr. Michael Golbey, chair of the CMA Board, said Tholl was not at the end of his contract, but that "he and the Board mutually agreed that he would depart."

Tholl is "proud as heck" of his years and accomplishments at CMA. "We've made CMA one of the most effective, if not the most effective, advocacy voices in Canada for health and health care." Tholl also lists making health human resources a priority of governments, and establishing a world meeting network concerning physician health and well-being, and a public health office, as among his accomplishments. He is also proud of the new governance structure for the $C M A J$.

"We've stabilized the CMAJ and put it on a new trajectory," Tholl says.

Tholl presided over the CMA when it dismissed Dr. John Hoey as editor-inchief of CMAJ, and Anne Marie Todkill as senior deputy editor, sparking

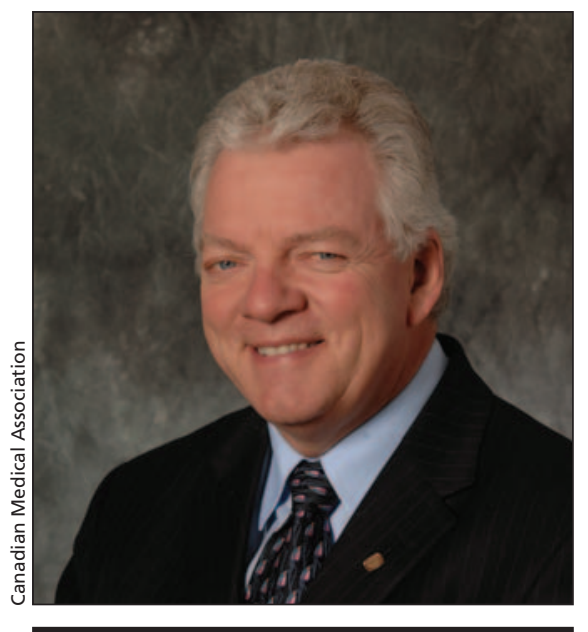

Ex-secretary general and chief executive officer William Tholl.

the resignations of many editorial staff and attracting global media attention. The controversy prompted the CMA to establish a governance review panel, which recommended a new governance structure to guarantee independence for $C M A J$ and negated the CMA's right to alter any content (CMAJ 2006;175[4]: 339-40).

Tholl plans to volunteer in the area of mental health and continue to advance the Canadian Health Leadership Network. He was recently appointed to the Royal Ottawa Hospital board.

Drew, who anticipates it will take 8 or 9 months to find a new chief executive officer, says the board is committed to the organization's current strategic plan. "I'm quite confident that CMA will go on quite well while we search for a new CEO, and under new leadership," Drew says. — Laura Eggertson, Ottawa, Ont.

DOI:10.1503/cmaj.081645 